\title{
Changes in nutritional status in adolescents surviving leukemia and lymphoma
}

\section{Alterações no estado nutricional em adolescentes sobreviventes de leucemias e linfomas}

Christy Hannah Sanini BELIN ${ }^{1}$ (D) 0000-0001-6805-2876

Márjory de Camillis BUENO1 (iD) 0000-0002-5560-7913

Luciane Beitler DA CRUZ² (ID) 0000-0002-2977-0696

Simone Geiger de Almeida SELISTRE ${ }^{3}$ (D) 0000-0003-2700-0281

Estela Beatriz BEHLING ${ }^{1}$ (iD) 0000-0001-9224-5723

\section{A B S T R A C T}

\section{Objective}

To examine the changes in the nutritional status of adolescents aged 10-19 years after a minimum 12 months interval following oncological treatment for leukemias and lymphomas.

\section{Methods}

Longitudinal design quantitative study conducted at Hospital de Clínicas, Porto Alegre. Adolescents aged 10-19 years after a minimum 12 months interval following oncological treatment for leukemias and lymphomas were included. The measures of weight, height, brachial circumference, triceps skinfold thickness, arm muscle circumference and abdominal circumference were collected.

\section{Results}

The sample comprised 50 adolescents who had survived leukemias and lymphomas. In the follow up $38 \%$ of the patients were classified as overweight according to the body mass index for their age. There was a significant

1 Universidade Federal do Rio Grande do Sul, Faculdade de Medicina, Departamento de Nutrição. R. Ramiro Barcelos, 2400, 4º andar, 90035-003, Porto Alegre, RS, Brasil. Correspondence to: EB BEHLING. E-mail: <ebehling@hcpa.edu.br>.

2 Universidade Federal do Rio Grande do Sul, Hospital de Clínicas de Porto Alegre, Serviço de Nutrição e Dietética. Porto Alegre, RS, Brasil.

3 Universidade Federal do Rio Grande do Sul, Hospital de Clínicas de Porto Alegre, Serviço de Oncologia Pediátrica. Porto Alegre, RS, Brasil.

Support: Fundo de Incentivo à Pesquisa, Hospital de Clínicas de Porto Alegre (Process n. 2016-0008).

How to cite this article

Belin CHS, Bueno MC, Cruz LB, Selistre SGA, Behlig EB. Changes in nutritional status in adolescents surviving leukemia and lymphoma. Rev Nutr. 2020;33:e190194. http://dx.doi.org/10.1590/1678-9865202033e190194 
increase in body mass index for age between the beginning and the end of treatment and follow up $(p=0.013)$ in female individuals, compared to males. The results indicate a reduction in the Z-score means of height for age, with significant differences between the beginning of treatment and follow up $(p=0.016)$; and end of treatment and follow up $(p=0.006)$ in patients of both genders.

\section{Conclusion}

The anthropometric indicators show an important frequency of excess weight and increased tricipital skinfold, as well as a significant increase of the body mass index for age and also a growth deficit among the survivors.

Keywords: Adolescent. Anthropometry. Leukemia. Lymphoma. Nutritional status.

\section{R E S U M O}

\section{Objetivo}

Verificar as alterações no estado nutricional em adolescentes de 10-19 anos, observadas após 12 meses, no mínimo, da conclusão de tratamento oncológico de leucemias e linfomas.

\section{Métodos}

Trata-se de estudo quantitativo de delineamento longitudinal realizado no Hospital de Clínicas de Porto Alegre. Foram incluídos adolescentes de 10-19 anos, que haviam concluído tratamento oncológico para leucemias e linfomas há no mínimo doze meses. Foram coletadas as medidas de peso, estatura, circunferência braquial, dobra cutânea tricipital, circunferência muscular do braço e circunferência abdominal.

\section{Resultados}

A amostra foi constituída por cinquenta adolescentes sobreviventes de leucemias e linfomas. No follow up, $38 \%$ dos pacientes foram classificados como excesso de peso de acordo com o índice de massa corporal para a idade. Houve um aumento significativo no índice de massa corporal para a idade, ocorrida entre o início do tratamento, seu fim e follow up $(p=0,013)$ nos indivíduos do sexo feminino, quando comparados a indivíduos do sexo masculino. Os resultados apontam uma diminuição nas médias de Escore-Z de estatura para a idade, com diferenças significativas entre o início do tratamento e follow up $(p=0,016)$ e entre término do tratamento e follow up $(p=0,006)$, em pacientes de ambos os sexos.

\section{Conclusão}

Os indicadores antropométricos demonstram uma frequência importante de excesso de peso e aumento da dobra cutânea tricipital, um aumento significativo do índice de massa corporal para a idade, bem como um deficit de crescimento entre os sobreviventes.

Palavras-chave: Adolescente. Antropometria. Leucemia. Linfoma. Estado Nutricional.

\section{INTRODUCTION}

Cancer is a group of diseases characterized by the uncontrollable growth and dissemination of abnormal cells [1]. Leukemias are the most frequent neoplasms in childhood, and Acute Lymphoblastic Leukemia (ALL) is the most prevalent [2]. Lymphomas are neoplasms that originate in the immune system cells and may infiltrate the bone marrow and other tissues. According to records of the Instituto Nacional do Câncer (INCA, National Cancer Institute) the incidence of new cases of lymphomas and leukemias in 2018 was 83,180 and 60,300, respectively [3].

Advances in antineoplastic treatments and in the care of children with cancer resulted in a significant increase in cancer cure rates [4]. This longer survival is accompanied by an increase in the chances of development of various late effects, such as premature mortality, osteoporosis, growth deficit, coronary artery disease, hypertension, secondary malignant neoplasms, psychosocial effects, metabolic disorders such as overweight, glucose intolerance, insulin resistance, and diabetes, due to chemotherapy and the use of high doses of corticosteroids [5-8]. Obesity in patients who survive 
childhood cancer may develop due to the oncological treatment itself, because of the reduction of physical activity, family-related factors, unhealthy nutrition, hormone changes and prolonged exposure to the use of corticosteroids [6,9].

Cancer and excess weight have a major impact on public health, since their late effects result in greater demands and expenditures for the health services. Since this is an important issue, the present study aimed at looking at the changes in the nutritional status of adolescents with leukemias and lymphomas from the beginning to the end of the treatment and in the follow up and its association with the treatment received.

\section{METHO D S}

This was a quantitative longitudinal study performed between February 2016 and March 2018 at the Hospital de Clínicas of Porto Alegre. The sample comprised patients aged 10 to 19 years treated in the outpatient department of the Pediatric Oncology Services, who had completed their oncological treatment at least 12 months before. Patients with Down syndrome were excluded.

Data collection was assessment during three moments: beginning of treatment (M1), end of treatment (M2), and in the follow up (M3). The height and weight measures described in the patient records were used at the beginning (M1) and end (M2) of treatment. The anthropometric evaluation in the follow up period (M3) was performed in a health room, where the weight was measured using a Toledo ${ }^{\circledR}$ balance and height with the help of a Holtain ${ }^{\circledR}$ stadiometer. The other anthropometric measures' data: Brachial Circumference (BC), Tricipital Skinfold (TSF), Arm Muscle Circumference $(A M C)$, and Abdominal Circumference $(A C)$ were collected using the methodology described by Frisancho [10] and Taylor et al. [11].

In order to establish the anthropometric classification of the nutritional status and for a nutritional diagnosis, the reference standard of the World Health Organization (WHO) was adopted [12]. This was done based on the Body Mass Index (BMI) parameters for Age (BMI/A) and Height for Age (H/A). To review the data, the software WHO Anthro Plus, 2009 version 1.0.3 [13]. was used, according to the WHO reference standard, considering the following cutoff points of the Z-score of BMI/A: thinness ( -2.00 to -3.00$)$; eutrophy $(-2$ to +1$)$; overweight $(+1.00$ to +2.00$)$; obesity $(+2.00$ to +3.00 ); and severe obesity (above +3.00$)$, overweight and obesity being grouped as excess weight. The following cutoff points were considered to classify the Z-score of Height for Age (H/A): very low height for age (less than -3.00); low height for age (-3.00 to -1.99); and appropriate height for age $(-2.00$ to +3.00$)[14]$.

The measures of $B C, A M C$ and TSF were evaluated according to the percentiles proposed by Frisancho [10], and the following indicators were adopted to evaluate $B C$ and $A M C: \angle p 5=10 w$; p5-p95= average; and >p95= overweight; TSF: <p5= low; p5-p85= average; and >p85= overweight [10].

In order to measure the abdominal circumference the cutoff points proposed by Taylor et al. for individuals aged 3 to 19 years were adopted [11]. The demographic and clinical data were collected using a questionnaire and the online record.

The results were analyzed by the IBM ${ }^{\circledR}$ PASW ${ }^{\circledR}$ (Program, version 18.0, Chicago, 2009) [15]. The Chi-Square test was performed, and expressed as percentage for the descriptive analysis of categorical variables. The association between the antineoplastic treatment and nutritional status 
was performed by means of the Chi-Square test. To compare the different time points and gender the ANOVA-MR test was used with Bonferroni post-hoc correction. The level of significance adopted was $5 \%$.

The "Nutritional status assessment in children and adolescents on leukemia and lymphoma treatment follow up at the Hospital de Clínicas of Porto Alegre" was a longitudinal study, carried out at Hospital de Clínicas of Porto Alegre, approved by the Hospital de Clínicas Research Ethics Committee under number 2016-0008, and it is in accordance with Resolution 466/12 of the National Health Council and the Declaration of Helsinki. All procedures with the participants were performed only after their signing the Informed Consent Form (ICF). The ICF was signed by all participants, by parents or guardians of underage patients and by the investigator who carried out the evaluation.

\section{RE S U L T S}

The sample comprised 50 patients. The mean age was $15( \pm 3.0)$ years and $62.0 \%$ of the patients were male. The median follow up time was 35.5 (18.75-78.25) months, with a minimum of 12 months and maximum of 136 months. As to the self-declared skin color, $76.0 \%$ of the patients stated they were white. The most prevalent type of cancer was ALL, responsible for $54.0 \%$ of the diagnoses. About the family disease history, 94.0\% patients indicated they had hypertension $(70.2 \%)$ - the most prevalent disorder - and diabetes Mellitus type 2 (46.8\%). The other clinical and demographic characteristics are shown in Table 1. The age at the beginning of the treatment varied from 1 year and 11 months to 17 years, with a mean age of 9.16 years. The mean time of oncological treatment was 25 weeks, the minimum time 3 weeks and the maximum 64 weeks.

Table 1. Sample characteristics. Hospital de Clínicas of Porto Alegre, 2006-2018.

\begin{tabular}{lcc}
\hline Variables & \multicolumn{2}{c}{ Participants $\left(\mathrm{N}=50^{\mathrm{a}}\right)$} \\
\hline Age & $\mathrm{M}=15.0$ & $\mathrm{SD}=3.0$ \\
Follow-up time in months & $\mathrm{Md}=35.5$ & $\mathrm{IQR}=18.75-78.25$ \\
Gender (male:female) & $\mathrm{n}$ & $\mathrm{\%}$ \\
\hline & & \\
\hline Skin complexion & 38 & 76.0 \\
White & 38.0 & 6.0 \\
Black & 3 & 18.0 \\
Mulatto & 9 & 54.0 \\
Cancer diagnosis & & 8.0 \\
ALL & 27 & 26.0 \\
LMA & 4 & 12.0 \\
Hodgkin lymphoma & 13 & 30.0 \\
Non Hodgkin lymphoma & 6 & 94.0 \\
Current use of drugs & 15 & 70.2 \\
Family history of diseases & 47 & 46.8 \\
Hypertension & 33 & 12.7 \\
Diabetes Mellitus type 2 & 22 & 6 \\
Hematological cancer & & \\
\hline
\end{tabular}

Note: ${ }^{\text {a}}$ Chi-Square test.

ALL: Acute Lymphoblastic Leukemia; IQR: Interquartile Range; LMA: Leukemia Myeloma Lymphoma; M: Mean; Md: Median; SD: Standard Deviation. 
Table 2 presented the values of the Z-score means of BMI/A and of $\mathrm{H} / \mathrm{A}$ in relation to the beginning (M1), and end (M2) of treatment and follow up (M3). For the BMI/A indicator, an increase was obtained in the Z-score when M1 was compared to M2, without a statistically significant difference between the two time points. No statistically significant difference was found in the Z-score of BMI/A comparing M3 to M1 and M2 ( $p=0.081)$. The results point to a reduction in the means of linear growth according to the Z-score for $\mathrm{H} / \mathrm{A}$, with statistically significant differences between M1 and M3 ( $p=0.016)$; and between M2 and M3 $(p=0.006)$. A difference was found in the BMI/A index between genders over time. In $\mathrm{M} 3$, the most prevalent nutritional status among male individuals was eutrophy $(67.7 \%)$, followed by overweight (29.0\%). As to the female individuals, excess weight was more prevalent $(52.6 \%)$, followed by eutrophy (47.4\%). The height was found to be appropriate in relation to age in $90.3 \%$ of the boys and in all girls.

The means and standard deviations of the BMI/A and H/A indexes and the classification of the nutritional status are described in Table 3. There was a prevalence of eutrophy in the population studied $(60.0 \%)$ and a height appropriate for age $(94.0 \%)$ in M3. Analyzing the anthropometric measures in M3, a 10.0\% frequency of overweight was found, considering the brachial circumference, $24.0 \%$ considering the tricipital skinfold, $10.0 \%$ the arm muscle circumference and $32.7 \%$ the abdominal circumference. The evaluation of the brachial circumference, arm muscle circumference indicating excess weight ( $p>95$ ) was associated with the Z-score BMI/A of overweight and obesity in $\mathrm{M} 3(p=0.001)$. In the evaluation of the tricipital circumference (>p85), excess weight, was associated with overweight and obesity nutritional status $(p=0.011)$. The evaluation of the abdominal circumference was associated with excess weight by $\mathrm{BMI} / \mathrm{A}(p<0.001)$.

The drugs used in the treatment were grouped in different classes, antibiotics, mitotic inhibitors, alkylating agents, antimetabolites, anthracyclines, corticosteroids, antifungals and others. As to the modalities of antineoplastic treatment, $100 \%$ of the patients underwent chemotherapy and $18(36 \%)$ also underwent radiotherapy. The drugs most used during antineoplastic treatment were antibiotics (96\%), mitotic inhibitors (90\%), anthracyclines (86\%), and corticosteroids (68\%). Table 4 shows the association of the drugs used in the antineoplastic treatment with the nutritional status of patients in M3. No significant association was found between the other drugs used and the patients' nutritional status.

Table 2. Mean values of the Z-score of the anthropometric indicators at the beginning (M1), and end of the treatment (M2) and at follow up (M3) in both genders. Hospital de Clínicas of Porto Alegre, 2006-2018.

\begin{tabular}{lcccc}
\hline Indicators & M1 & M2 & M3 & Value $p^{\text {a }}$ \\
\hline Z-score BMI/A & $0.266( \pm 1.916)$ & $0.652( \pm 1.496)$ & $0.612( \pm 1.263)$ & 0.081 \\
Female & $0.207(1.50)$ & $1.266(1.21)$ & $1.129(1.17)$ & $0.013^{*}$ \\
Male & $0.301(2.15)$ & $0.287(1.55)$ & $0.295(1.22)$ & $0.004^{*}$ \\
Z-score H/A & $0.056( \pm 1.242)^{1}$ & $0.522( \pm 1.081)^{1}$ & $-0.285( \pm 0.966)^{2}$ & 0.138 \\
Female & $0.346(1.10)$ & $0.208(1.12)$ & $0.076(1.03)$ & $-0.507(0.91)$ \\
Male & $-0.129(1.30)$ & $0.043(1.06)$ &
\end{tabular}

Note: "Difference betwen female and male; aANOVA test for multiple responses with post-hoc Bonferroni; ${ }^{1,2}$ Different numbers represent statistically different means; Statistical significance: $p \leq 0.05$.

BMI/A: Body Mass Index/Age; H/A: Height/Age. 
Table 3. Mean and Standard deviation of the Z-score values and classification of the nutritional status of patients during the follow up period. Hospital de Clínicas of Porto Alegre, 2006-2018.

\begin{tabular}{|c|c|c|c|c|}
\hline \multirow{2}{*}{ Index } & \multicolumn{4}{|c|}{ Participants } \\
\hline & M & SD & $\mathrm{N}$ & $\%^{a}$ \\
\hline Z-score BMl/A & 0.612 & 1.26 & & \\
\hline Thinness ( $\geq Z$-score $Z<-2$ ) & & & 1 & 2.0 \\
\hline Eutrophy ( $\geq Z$-score Z -2 and $\leq+1$ ) & & & 30 & 60.0 \\
\hline Excess weight $(>Z+1$ score and $\leq Z+3$ score & & & 19 & 38.0 \\
\hline Z-score H/A & -0.285 & 0.99 & & \\
\hline Very low height for age (<Z-3 score) & & & 0 & 0.0 \\
\hline Low height for age ( $\geq$ score Z-3 and $<-2$ ) & & & 3 & 6.0 \\
\hline Height adequate for age ( $\geq Z-2$ score) & & & 47 & 94.0 \\
\hline \multicolumn{5}{|l|}{ Brachial circumference } \\
\hline Below $(<\mathrm{p} 5)$ & & & 6 & 12.0 \\
\hline Mean (p5-p95) & & & 39 & 78.0 \\
\hline Excess fat (>p95) & & & 5 & 10.0 \\
\hline \multicolumn{5}{|l|}{ Tricipital skinfold } \\
\hline Low $(<\mathrm{p} 5)$ & & & 1 & 2.0 \\
\hline Mean (p5-p85) & & & 37 & 74.0 \\
\hline Excess fat (>p85) & & & 12 & 24.0 \\
\hline \multicolumn{5}{|l|}{ Arm muscle circumference } \\
\hline Low $(<\mathrm{p} 5)$ & & & 5 & 10.0 \\
\hline Mean (p5-p95) & & & 40 & 80.0 \\
\hline Excess fat (>p95) & & & 5 & 10.0 \\
\hline \multicolumn{5}{|l|}{ Abdominal circumference } \\
\hline Excess abdominal fat (>p80) & & & 16 & 32.7 \\
\hline
\end{tabular}

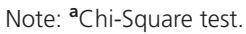

BMI/A: Body Mass Index/Age; H/A: Height Index/Age; p: Percentile; M: Mean; SD: Standard Deviation.

Table 4. Association between antineoplastic treatment and nutritional status in survivors of childhood cancer during the M3 period. Hospital de Clínicas of Porto Alegre, 2006-2018.

\begin{tabular}{|c|c|c|c|c|c|c|}
\hline \multirow{2}{*}{ Medications } & \multirow{2}{*}{ Participants (n) } & \multicolumn{2}{|c|}{ Eutrophy } & \multicolumn{2}{|c|}{ Excess Weight } & \multirow{2}{*}{ Value $p$} \\
\hline & & $M$ & $\%$ & $M$ & $\%$ & \\
\hline Alkylating agents & 39 & 22 & 55.0 & 17 & 42.5 & $0.429^{a}$ \\
\hline Anthracyclines & 42 & 24 & 80.0 & 18 & 94.7 & $0.335^{a}$ \\
\hline Antimetabolics & 32 & 20 & 60.6 & 12 & 36.3 & $1.000^{a}$ \\
\hline Antifungals & 18 & 12 & 63.1 & 6 & 31.5 & $0.434^{a}$ \\
\hline Antibiotics & 47 & 30 & 62.5 & 17 & 35.4 & $1.810^{\mathrm{a}}$ \\
\hline Mitotic inhibitors & 44 & 25 & 55.5 & 19 & 42.2 & $0.228^{\mathrm{a}}$ \\
\hline Corticosteroids & 34 & 19 & 55.8 & 15 & 44.1 & $0.192^{\mathrm{a}}$ \\
\hline Others $^{1}$ & 49 & 30 & 61.2 & 19 & 38.7 & - \\
\hline
\end{tabular}

Note: ${ }^{a}$ Chi-Square test; ${ }^{1}$ Acyclovir, Amlodipine Besylate, Amlodipine, Captopril, Digoxin, Dimenhydrinate, Diphenhydramine Chlorhydrate, Farmanguinhos Oseltamivir, Fluoxetine Chlorhydrate, Folic Acid, Hydralazine Chlorhydrate, Lactulose, Loratadine, Metformin Chlorhydrate, Omeprazole, Ondansetron Chlorhydrate, Oseltamivir, Paracetamol, Ranitidine Chlorhydrate, Rasburicase, Recombinant Human Insulin and Lispro, Risperidone, Sertraline Chlorhydrate, Sodium Valproate, Tacrolimus, Vitamin K; M: Mean.

\section{DISCUSSION}

This study evaluated the nutritional status of survivors of leukemias and lymphomas in childhood in outpatient care at a university hospital in Southern Brazil. Leukemia is the most common 
type of neoplasm among the pediatric population [3]. This higher prevalence was observed in our study as in other studies in children with leukemia such as in Iran and in Southern Brazil $[16,17]$. There was a higher prevalence of male, white patients, as also observed in other studies $[18,19]$.

Survivors of cancer in childhood presented late effects that may appear earlier or over the long term, such as growth deficit and excess weight in female individuals. Studies have shown a major prevalence of excess weight in patients who are cancer survivors, especially in those with a high $\mathrm{BMI}$ at diagnosis $[20,21]$. In the present study there was an increase in the Z- score BMI/A indicator between $\mathrm{M} 1$ and $\mathrm{M} 2$, as well as between $\mathrm{M} 1$ and $\mathrm{M} 3$. Although this increase was not statistically significant $(p=0.081)$, these results corroborated another study that found a significant increase of the mean of the Z scores of BMI/A in M3 [22]. Oliveira et al. [22] also observed that the survivors exhibited excess weight at the beginning, and at the end of the treatment and at follow up, concluding that these individuals presented a higher risk for the development of chronic diseases. Based on the BMI/A measures, Nakhaei-Moghadam et al. [16] found a prevalence of $29.2 \%$ overweight and $16.7 \%$ obesity, and no association between patients' weight gain and type of treatment, gender and age. According to other studies the prevalence of obesity after antineoplastic treatment of ALL in childhood varies from $16 \%$ to $56 \%$ approximately, and may be related to cranial radiation, treatment with corticosteroids, physical inactivity and increased calories intake [8,21]. Our study found a higher patients' eutrophy prevalence in $\mathrm{M} 3$, corroborating the data from other investigations, where the patients who survived leukemias were eutrophic utilizing the same parameters as BMI/A [17]. Different results were obtained in a case-control study where the survivors of ALL in childhood were at greater risk for overweight or obesity during follow up compared to the Control Group; a significant difference in the mean weight and BMI was found, both of them being greater in the ALL survivors [21].

Distinct results are reported in the literature with regard to gender and weight gain of cancer survivors. A few studies concluded that male individuals have a greater propensity to gain weight compared to female individuals during the treatment, and this is in line with the differences identified among genders in the pediatric population [23]. A retrospective study that evaluated children with $A L L$, analyzing the Z-scores of BMI, height and weight per gender, found that male individuals had a significantly larger BMI, while females showed a greater increase in the Z-score of BMI over seven years of follow up compared to their BMI at the time of diagnosis [6]. Other studies indicate that women are at greater risk for obesity or for persisting in a nutritional state of obesity for a longer period after chemotherapy, and it is essential to prevent weight gain and complications over the long term as a result of obesity [9], similarly to what happened with the population studied, that presented a significant difference in the BMI/A index in the female gender over time.

Acute Lymphoblastic Leukemia survivors appear to present a deficit in the Z-score of height during chemotherapy and an increase in the BMI indexes, which is not followed by an appropriate catch up with growth [24]. Evaluating the Height per Age Index most of the patients had an adequate height for their age similar to the data found in another study [17]. However, studies have observed a significant reduction in the Z-scores of Height per Age Index overtime in children with ALL [6]. Our study found a statistically significant difference in relation to height for age between $\mathrm{M} 1$ and M3 ( $p=0.016)$; and between M2 and M3 $(p=0.006)$, demonstrating a possible deficit in growth over treatment. It is known that reduction in linear growth is a common finding in cancer survivors, although most of the survivors treated with chemotherapy reach normal height and puberty when adults [25].

Studies have shown prevalence of overweight and obesity associated with a growth deficit in pediatric patients receiving chemotherapy $[22,26]$. Several factors have been associated with 
changes in linear growth, such as the disease itself, poor nutrition, chemotherapy, and growth hormone deficiency secondary to cranial irradiation [27]. Patients undergoing radiotherapy treatment associated with corticotherapy had a higher growth deficit at the end of the treatment when compared to patients receiving only glucocorticoids [28]. Corticosteroid therapy is often associated with overweight and obesity in survivors of childhood cancer [21].

In the present study, no significant association was found between the nutritional status of the survivors and the drugs used in the antineoplastic treatment. Studies have evidenced that a few medications, such as corticosteroids may increase BMI during treatment due to the increased consumption of foods, but their long term effect is still arguable $[6,29,30]$; nevertheless, in our study this association was not observed.

Arm anthropometry is recommended as a tool to evaluate nutritional status because it is very sensitive [25]. The consensus of Brazilian oncological nutrition specialists describes TSF as one of the variables for nutritional diagnosis to be used before, during and after chemotherapy and radiotherapy in children over the age of 2 years [31]. Measuring body fat using the tricipital skinfold enables measuring both the quantity and the body distribution of adipose tissue, thus meaning a better correlation with the excess weight than BMI [25,32]. In the sample studied we found $24.0 \%$ excess fat with this measure. The evaluation of the tricipital circumference to measure excess weight was also associated with the nutritional status of overweight and obese patients in a study performed with the survivors of ALL in childhood and adolescence. It is considered a useful measure to identify excess weight in this population. We found an association between the brachial circumference, the arm muscle circumference and the BMI/A of overweight and obese patients in M3. Findings by Collins et al. [32] demonstrate a positive correlation between BMI and the muscle circumference of the arm in ALL survivors [30].

Waist circumference is a strong predictor of cardiometabolic risk in children [26]. In our study the abdominal circumference was associated with excess weight using the variable BMI/A $(p<0,001)$. In the evaluation of the metabolic alterations in children and adolescents who survived cancer and were treated with chemotherapy, Soto-Vega [30] found a correlation between increased triglycerides, cholesterol and waist circumference. Few studies investigated relations between life style, obesity, and risk factors for cardiovascular disease in childhood cancer survivors. Research data suggest that cancer survivors in childhood and adolescence present harmful eating habits and a high consumption of energy [33].

Modifications in weight, BMI, hip circumference, and also triglycerides and cholesterol, can be found and related to metabolic syndrome in children who are undergoing chemotherapeutic treatment [30]. One of the limitations of this study was that the sample size did not allow a detailed analysis of the differences between age and groups of diseases.

\section{CONCLUSION}

The patients in this study presented a greater Z-score of the BMI/A index in the follow up, compared to the patients at the beginning of treatment, and also presented a growth deficit at the end of the treatment and on M3. These findings demonstrate the need to evaluate and perform nutritional interventions at all stages of treatment, and also to perform further studies on the subject in order to promote a more adequate evaluation of the nutritional status in adolescents who have survived leukemia and lymphoma. 


\section{REFERE N CES}

1. American Cancer Society. Cancer Facts \& Figures 2017. Atlanta: Society; 2017 [cited 2019 Sept 7]. Available from: https://www.cancer.org/content/dam/cancer-org/research/cancer-facts-and-statistics/annual-cancerfacts-and-figures/2017/cancer-facts-and-figures-2017.pdf

2. Friestino JKO, Mendonça D, Oliveira P, Oliveira CM, Moreira DCF. Childhood cancer: incidence and spatial patterns in the city of Campinas, Brazil, 1996-2005. Salud Colect. 2018;14(1):51-63. http://dx.doi. org/10.18294/sc.2018.1200

3. Noone A, Howlader N, Krapcho M, Miller D, Brest A, Yu M, et al. SEER Cancer Statistics Review 1975-2015. Bethesda: National Cancer Institute; 2018.

4. Hunger SP, Mullighan CG. Acute lymphoblastic leukemia in children. N Engl J Med. 2015;373(16):1541-52. http://dx.doi.org/10.1056/nejmra1400972

5. Ahmad SS, Reinius MAV, Hatcher HM, Ajithkumar TV. Anticancer chemotherapy in teenagers and young adults: managing long term side effects. BMJ. 2016;354:1-8. http://dx.doi.org/10.1136/bmj.i4567

6. Touyz LM, Cohen J, Neville KA, Wakefield CE, Garnett SP, Mallitti KA, et al. Changes in body mass index in long-term survivors of childhood acute lymphoblastic leukemia treated without cranial radiation and with reduced glucocorticoid therapy. Pediatr Blood Cancer. 2017;64(4):e26344. http://dx.doi.org/10.1002/ pbc. 26344

7. Chemaitilly W, Cohen LE. Endocrine late-effects of childhood cancer and its treatments. Eur J Endocrinol. 2017;176:183-203. http://dx.doi.org/10.1530/eje-17-0054

8. Teixeira JFC, Lemos PSM, Cypriano MS, Pisani LP. The influence of antineoplastic treatment on the weight of survivors of childhood cancer. J Pediatr. 2016; 92:559-66. http://dx.doi.org/10.1016/j.jped.2016.04.003

9. Zhang FF, Parsons SK. Obesity in childhood cancer survivors: call for early weight management. Adv Nutr. 2015;6(5):611-9. http://dx.doi.org/10.3945/an.115.008946

10. Frisancho AR. Anthropometric standards for the assessments of growth and nutritional status. Clin Nutr. $1991 ; 10(2): 131-2$

11. Taylor RW, Jones IE, Williams SM, Goulding A. Evaluation of waist circumference, waist-to-hip ratio, and the conicity index as screening tools for high trunk fat mass, as measured by dual energy $\mathrm{X}$-ray absorptiometry, in children aged 3-19 y. Am J Clin Nutr. 2000;72:490-5.

12. World Health Organization. WHO Child Growth Standards: length/height-for-age, weight-for-age, weight-for-length, weight-for-height and body mass index-for-age: methods and development. Geneva: Organization; 2006.

13. World Health Organization. WHO AnthroPlus for personal computers [software]. Geneva: Organization, 2009.

14. De Onis M, Onyango AW, Borghi A, Amani Siyam A, Nishidaa C, Siekmann J. Development of a WHO growth reference for school-aged children and adolescents. Bull World Health Organ. 2007;85(9):660-7.

15. International Business Machines Corporation. Statistical Package for Social Sciences. Version 18.0 [software]. Chicago: IBM; 2009.

16. Nakhaei-Moghadam M, Setoodeh A, Noori N, Rostami P, Teimouri A. Endocrine and metabolic disorders in children with cancer treatment. Zahedan J Res Med Sci. 2016;18(3):e6244. http://dx.doi.org/10.17795/ zjrms-6244

17. Sousa TS, Santos LTG, Sousa P, Sousa RML, Martins ICVS, Dias LPP, et al. Indicadores antropométricos em crianças com câncer em um hospital de referência. Rev Pesq Saúde. 2016;17(3):151-3.

18. Wilson CL, Howell CR, Partin RE, Lu L, Kaste SC, Mulrooney DA, et al. Influence of fitness on health status among survivors of acute lymphoblastic leukemia. Pediatr Blood Cancer. 2018;65:e27286. http://dx.doi. org/10.1002/pbc.27286

19. Rashedy FH, Hawy A, Hefnawy SM, Mohammed MM. Assessment of obesity and hepatic late adverse effects in the egyptian survivors of pediatric acute lymphoblastic leukemia: a single center study. Mediterr J Hematol Infect Dis. 2017;9:1-7. http://dx.doi.org/10.4084/mjhid.2017.026

20. Elitzur S, Houri-Shtrecher R, Yackobovitz-Gavan M, Urasiński T. Growth and pubertal patterns in young survivors of childhood acute lymphoblastic leukemia. J Pediatr Endocrinol Metab. 2017;30(8):869-77. http:// dx.doi.org/10.1515/jpem-2017-0099 
21. Bayram C, Yarali N, Fettah A, Demirel F, Tavil B, Kara A, et al. Evaluation of endocrine late complications in childhood acute lymphoblastic leukemia survivors: A Report of a Single-Center Experience and Review of the Literature. Turk J Haematol. 2017;34(1):40-5. http://dx.doi.org/10.4274/tjh.2015.0332

22. Oliveira B, Lins M, Pedrosa F, Cabral PC, Barbosa JM. Estado nutricional de crianças e adolescentes sobreviventes de leucemia linfóide aguda, tratados em um Centro de Referência da Região Nordeste do Brasil. Rev Nutr. 2013;26(3):271-81.

23. Belle FN, Wenke-Zobler J, Cignacco E, Spycher BD, Ammann RA, Kuehni CE, et al. Overweight in childhood cancer patients at diagnosis and throughout therapy: a multicentre cohort study. Clin Nutr. 2019;38(2):835-41. http://dx.doi.org/10.1016/j.clnu.2018.02.022

24. Antal Z, Balachandar S. Growth disturbances in childhood cancer survivors. Horm Res Paediatr. 2019;91(2):83-92. http://dx.doi.org/10.1159/000496354

25. Shah $\mathrm{P}$, Jhaveri $U$, Idhate TB, Dhingra S, Arolkar P, Arora B. Nutritional status at presentation, comparison of assessment tools, and importance of arm anthropometry in children with cancer in India. Ind J Cancer. 2015;52(2):210-5. http://dx.doi.org/10.4103/0019-509x.175838

26. Sharma AK, Metzger DL, Daymont C, Hadjiyannakis S, Rodd CJ. LMS tables for waist-circumference and waist-height ratio Z-scores in children aged 5-19 y in NHANES III: association with cardio-metabolic risks. Pediatr Res. 2015;78(6):723-9. http://dx.doi.org/10.1038/pr.2015.160

27. Ness K, Gurney JG. Adverse late effects of childhood cancer and its treatment on health and performance. Annu Rev Public Health 2007;28(1):279-302. http://10.1146/annurev.publhealth.28.021406.144049

28. Silva CHBA, Kuperman H, Dichtchekenian V, Damiani D, Della Manna T, Cristofani LM, et al. Growth and puberty after treatment for acute lymphoblastic leukemia. Rev Hosp Clin Fac Med S Paulo. 2004;59(2):67-70.

29. Ripka WL, Ulbricht L, Gewehr PM. Body composition and prediction equations using skinfold thickness for body fat percentage in Southern Brazilian adolescents. Plos One. 2017;12(9):1-13. http://dx.doi.org/10.1371/ journal.pone. 018485

30. Soto-Vega E, Carrillo-Vicente LS, Vázquez JC, Pérez de Celis Herrero MC, Muñoz-Pérez MJ. Metabolic Changes in Children that Received Chemotherapy. J Pediatr Hematol Oncol. 2019;41(6):448-51. http:// dx.doi.org/10.1097/mph.0000000000001401

31. Instituto Nacional de Câncer (Brasil). Consenso Nacional de Nutrição Oncológica. 2 ed. Rio de Janeiro: Instituto; 2016.

32. Collins L, Beaumont L, Cranston A, Savoie S, Nayiager T, Barr R. Anthropometry in long-term survivors of acute lymphoblastic leukemia in childhood and adolescence. J Adolesc Young Adult Oncol. 2017;6(2):294-8. http://dx.doi.org/10.1089/jayao.2016.0091

33. Kopp LM, Gastelum Z, Guerrero CH, Howe CL, Hingorani P, Hingle M. Lifestyle behavior interventions delivered using technology in childhood, adolescent, and young adult cancer survivors: a systematic review. Pediatr Blood Cancer. 2017;64:13-7. http://dx.doi.org/10.1002/pbc.26166 